\title{
PENGARUH KEPEMIMPINAN DAN KOMUNIKASI TERHADAP KINERJA DOSEN DENGAN BUDAYA ORGANISASI SEBAGAI VARIABEL INTERVENING PADA STIE SULTAN AGUNG PEMATANGSIANTAR
}

\author{
Oleh: \\ Fitria Halim \\ Dosen STIE Sultan Agung Pematangsiantar
}

Abstraksi

Penelitian ini bertujuan untuk menguji pengaruh kepemimpinan dan komunikasi terhadap kinerja dosen dengan budaya organisasi sebagai variabel intervening baik secara parsial maupun simultan.

Sampel pada penelitian ini adalah semua dosen pada STIE Sultan Agung Sultan Agung Pematangsiantar yang berjumlah 45 Orang. Data dalam penelitian ini adalah data primer. Data dikumpulkan dengan menggunakan kuesioner yang dibagikan langsung kepada responden. Metode analisa data yang digunakan adalah Analisa Kuantitatif dan Analisa Kualitatif. Analisis Kuantitatif menggunakan aplikasi SPSS versi 17.

Hasil penelitian dan uji hipotesis menunjukkan bahwa variabel kepemimpinan dan komunikasi berpengaruh signifikan terhadap kinerja dosen baik secara parsial maupun simultan. Variabel budaya organisasi mengintervening pengaruh kepemimpinan dan komunikasi terhadap kinerja dosen.

Kata Kunci : Kepemimpinan, Komunikasi, Budaya Organisasi, dan Kinerja Dosen

\section{Abstraction}

The objective of this research was to test the influence of leadership and communication toward the lecturer performance with organization culture as intervening variable in a partial and simultaneous way.

The sample of this research was all lecturer in STIE Sultan Agung Pematangsiantar whose numbers were 45 peoples. Research data were primary data. Data were collected by using questionnaires which were distributed directly to the respondents. Analyzing method used was Quantitative Analysis and Qualitative Analysis. Quantitative Analysis proceed with application of SPSS version 17.

The findings of this research and hypothesis test showed that leadership and communication had significant influence to the lecturer performance partially and simultaneously. Variable of organization culture do intervening leadership and communication to the lecturer performance.

Keywords : Leadership, Communication, Organization Culture, and Lecturer Performance

\section{A. PENDAHULUAN}

1. Latar Belakang Masalah

STIE Sultan Agung Pematangsiantar adalah suatu instansi atau lembaga pendidikan dibawah naungan Yayasan Perguruan Sultan Agung memiliki dosen sebagai tenaga kerja untuk mencapai visi Yayasan Perguruan Sultan Agung yakni unggul dalam prestasi berdasarkan rasa percaya diri, iman dan taqwa.

Dalam rangka untuk mewujudkan hal tersebut diperlukan komponen yang saling mendukung yang salah satunya adalah kinerja dosen yang baik. Kinerja dosen sebagai kunci keberhasilan pendidikan, karena keberadaan dosen sangat berpengaruh terhadap semua sumber daya pendidikan yang dimiliki, seperti sarana dan prasarana, biaya, teknologi, informasi, mahasiswa, orang tua mahasiswa dan masyarakat. Pemberdayaan sumber daya ini dapat dicapai dengan baik apabila dosen memiliki kemampuan yang baik pula dalam menggunakan semua sumber daya yang ada.

\section{Rumusan Masalah}

a. Apakah kepemimpinan dan komunikasi mempunyai pengaruh yang signifikan terhadap kinerja dosen STIE Sultan Agung Pematangsiantar secara simultan?

b. Apakah budaya organisasi mempunyai pengaruh yang signifikan terhadap kinerja dosen STIE Sultan Agung Pematangsiantar secara parsial?

c. Apakah budaya organisasi mengintervening pengaruh kepemimpinan terhadap kinerja dosen STIE Sultan Agung Pematangsiantar?

d. Apakah budaya organisasi mengintervening pengaruh komunikasi terhadap kinerja dosen STIE Sultan Agung Pematangsiantar?

\section{Tujuan Penelitian}

a. Untuk mengetahui dan menganalisis pengaruh kepemimpinan dan komunikasi terhadap kinerja dosen STIE Sultan Agung Pematangsiantar secara simultan.

b. Untuk mengetahui dan menganalisis pengaruh budaya organisasi terhadap kinerja dosen STIE Sultan Agung Pematangsiantar secara parsial.

c. Untuk mengetahui dan menganalisis apakah budaya organisasi mengintervening pengaruh kepemimpinan terhadap kinerja dosen STIE Sultan Agung Pematangsiantar.

d. Untuk mengetahui dan menganalisis apakah budaya organisasi mengintervening pengaruh 
komunikasi terhadap kinerja dosen STIE Sultan Agung Pematangsiantar.

\section{Metode Penelitian}

Adapun desain penelitian yang digunakan dalam penulisan penelitian ini adalah penelitian keputusan (library research), Penelitian lapangan (Field Research). Teknik pengumpulan data yang dipergunakan dalam penelitian ini adalah metode wawancara, metode kuisioner, metode dokumentasi.

\section{B. LANDASAN TEORI}

\section{Manajemen Sumber Daya Manusia}

Suatu organisasi akan berkembang apabila memiliki sumber daya manusia yang berkualitas. Untuk mewujudkannya, organisasi tersebut perlu melakukan manajemen sumber daya manusia. Menurut Dessler (2004:5), "manajemen sumber daya manusia adalah proses memperoleh, melatih, menilai, dan memberikan kompensasi kepada karyawan, memerhatikan hubungan kerja mereka, kesehatan, keamanan, dan masalah keadilan."

Dari uraian di atas, penulis menyimpulkan bahwa manajemen sumber daya manusia adalah ilmu dan seni yang mengatur hubungan dan peranan tenaga kerja untuk memastikan penggunaan bakat manusia secara efektif dan efisien guna mencapai tujuan-tujuan organisasional.

\section{Kepemimpinan}

Kepemimpinan merupakan proses yang harus ada dan perlu diadakan dalam kehidupan manusia selaku mahkluk sosial. Kepemimpinan diartikan sebagai pelaksanaan otoritas dan pembuatan keputusan. Kepemimpinan juga didefenisikan sebagai suatu inisiatif untuk bertindak yang menghasilkan suatu pola yang konsisten dalam rangka mencari jalan pemecahan dari suatu persoalan secara bersama.

Selanjutnya dikatakan bahwa tugas seorang pemimpin bisa dideskripsikan dalam bermacam peran atau perilaku yang diidentifikasikan dengan satu posisi tertentu. Status yang muncul sebagi konsekuensi dari otoritas formal yang dimiliki seorang pemimpin memunculkan tiga peran interpersonal (hubungan antar manusia), yang pada gilirannya memunculkan tiga peran informasional (berkaitan dengan informasi), dan selanjutnya kedua peran tersebut memungkinkan pemimpin untuk memainkan peran desisional (berkaitan dengan pengambilan keputusan). Berikut penjelasan mengenai peran kepemimpinan menurut $\mathrm{H}$. Mintzberg dalam tulisannya yang berjudul 'The Manager's Job: Folklore and Fact' dalam Harvard Business Review Vol 53, 1975 :

a) Peran Interpersonal (Interpersonal Role)

Dalam peran interpersonal terdapat tiga peran pemimpin yang muncul secara langsung dari otoritas formal yang dimiliki pemimpin dan mencakup hubungan interpersonal dasar, yaitu :

1) Peran sebagai yang dituakan (Figurehead Role)
2) Peran sebagai pemimpin (Leader Role)

3) Peran sebagai Penghubung (Liaison Role)

b) Peran Informasional (Informational Role)

Dikarenakan kontak interpersonalnya, baik dengan bawahan maupun dengan jaringan kontaknya yang lain, seorang pemimpin muncul sebagai pusat syaraf bagi unit organisasinya. Pemimpin bisa saja tidak tahu segala hal, tetapi setidaknya tahu lebih banyak dari pada anggotanya. Pemrosesan informasi merupakan bagian utama (key part) dari tugas seorang pemimpin. Tiga peran pemimpin berikut ini mendiskripsikan aspek informasional tersebut.

1) Peran sebagai monitor (Monitor Role)

2) Peran sebagai disseminator (Disseminator role)

3) Peran sebagai Juru bicara (Spokesman Role)

c. Peran Pengambilan Keputusan (Decisional Role) Informasi yang diperoleh pemimpin bukanlah tujuan akhir, tetapi merupakan masukan dasar bagi pengambilan keputusan. Sesuai otoritas formalnya, hanya pemimpinlah yang dapat menetapkan komitmen organisasinya ke arah yang baru dan sebagai pusat syaraf organisasi, hanya dia yang memiliki informasi yang benar dan menyeluruh yang bisa dipakai untuk memutuskan strategi organisasinya. Berkaitan dengan peran pemimpin sebagai pengambil keputusan terdapat empat peran pemimpin, yaitu:

1) Peran sebagai wirausaha (Entrepreneur Role)

2) Peran sebagai pengendali gangguan (Disturbance Handler Role)

3) Peran sebagai yang mengalokasikan sumberdaya (Resource Allocator Role)

4) Peran sebagai negosiator (Negotiator Role)

\section{Komunikasi}

Davis (2007:150) mengatakan "komunikasi adalah penyampaian (transfer) informasi dan pengertian dari satu orang kepada orang lain. Komunikasi merupakan cara menyampaikan gagasan, fakta, pikiran, perasaan, dan nilai kepada orang lain."

Komunikasi adalah jembatan arti di antara orang-orang sehingga mereka dapat berbagi hal-hal yang mereka rasakan dan ketahui. Dengan menggunakan jembatan ini, seseorang dapat menyeberangi sungai kesalahpahaman dengan selamat yang adakalanya memisahkan orang-orang. Komunikasi menduduki suatu tempat yang utama karena susunan keluasan dan cakupan organisasi secara keseluruhan ditentukan oleh teknik komunikasi. Dari sudut pandang ini komunikasi adalah suatu proses sosial yang mempunyai relevansi terluas di dalam memfungsikan setiap kelompok, organisasi atau masyarakat.

Proses komunikasi dalam struktur formal tersebut pada hakikatnya dapat dibedakan menjadi tiga dimensi seperti yang dijelaskan oleh Rivai (2003:377-378): 
a. Dimensi vertikal adalah dimensi komunikasi yang mengalir dari atas ke bawah dan sebaliknya.

b. Dimensi horizontal adalah penerimaan atau pengiriman berita atau informasi yang dilakukan antar pejabat yang mempunyai kedudukan yang sama.

c. Dimensi luar organisasi adalah dimensi komunikasi yang timbul sebagai akibat dari suatu organisasi yang tidak bisa hidup sendirian, ia merupakan bagian dari lingkungannya.

\section{Budaya Organisasi}

Setiap perusahaan atau organisasi tidak terlepas dari ikatan budaya yang diciptakan. Budaya yang kuat akan memberikan stabilitas bagi organisasi tersebut, tetapi bagi sebagian organisasi, budaya yang kuat dapat menjadi hambatan besar untuk berubah. Menurut Robbins dan Timothy (2008:256), "budaya organisasi merupakan sebuah sistem bersama yang dianut para anggota yang membedakan suatu organisasi dengan organisasi lainnya."

Menurut Luthans (2006:125), budaya organisasi memiliki beberapa karakteristik penting yaitu sebagai berikut:

a. Aturan-aturan perilaku, yang dapat dijadikan pedoman dalam hubungan antara anggota organisasi, komunikasi, terminologi, dan upacara-upacara (ritual).

b. Norma-norma, berupa aturan-aturan tak tertulis yang menentukan bagaimana cara bekerja.

c. Nilai-nilai dominan, mengandung konsepsi yang jelas atau keyakinan tentang hal-hal yang diinginkan atau diharapkan oleh anggota organisasi, seperti konsepsi nilai tentang kualitas, efisiensi tinggi, absensi rendah dan sebagainya.

d. Filosofi, berkaitan dengan kebijaksanaan organisasi menyangkut cara memperlakukan anggota organisasi dan pihak-pihak yang berkepentingan

e. Peraturan-peraturan, yang berisi petunjuk tentang pelaksanaan tugas-tugas dalam organisasi.

f. Iklim organisasi, yang menggambarkan lingkungan fisik organisasi, perilaku hubungan antara anggota, juga hubungan organisasi dengan pihak-pihak luar organisasi.

\section{Kinerja Dosen}

Dalam Undang-undang Guru dan Dosen No.4 Tahun 2005 tentang Guru dan Dosen, dalam Pasal 3, ayat 1 dikemukakan "dosen mempunyai kedudukan sebagai tenaga professional pada jenjang pendidikan tinggi yang diangkat sesuai dengan peraturan perundang-undangan." Lebih jauh dikemukakan bahwa dosen adalah pendidik profesional dan ilmuwan dengan tugas utama menstransformasikan, mengembangkan, dan menyebarluaskan ilmu pengetahuan, teknologi, dan seni melalui pendidikan, penelitian, dan pengabdian kepada masyarakat. Tugas utama dosen adalah sebagai pendidik, dosen mengemban tugas dan tanggung jawab untuk mendidik mahasiswa menjadi individu yang memiliki kemampuan dan kecakapan yang berguna bagi kehidupannya dan diperlukan untuk memasuki dunia kerja, melalui kemampuannya mengajar berbagai ilmu pengetahuan dan keterampilan, di samping tanggung jawab dalam bentuk sikap dan perilaku yang benar dan tidak benar dalam bertindak melalui sifat ketauladannya sebagai manusia yang bermoral.

Tugas dan tanggung jawab dosen yang diamanatkan dalam Tri Dharma Perguruan Tinggi mencakup pendidikan dan pengajaran, penelitian dan kegiatan pengabdian kepada masyarakat (Undang-Undang Nomor 12 tahun 2012 tentang Perguruan Tinggi adalah pendidikan dan pengajaran, penelitian dan penulisan karya ilmiah, dan kegiatan pengabdian kepada masyarakat.

\section{PEMBAHASAN}

\section{Analisa}

\section{a. Deskriptif Kualitatif}

Analisis deskripitif dimaksudkan untuk mendapatkan gambaran atau deskripsi mengenai tanggapan dari karyawan mengenai pengaruh kepemimpinan dan komunikasi terhadap kinerja dosen dengan budaya organisasi sebagai variabel intervening pada STIE Sultan Agung Pematangsiantar, sesudah pengujian data, maka langkah selanjutnya peneliti melakukan pengkajian analisa kualitatif sebagai gambaran fenomena dari variabel penelitian pada saat sekarang ini.

\section{b. Deskriptif Kuantitatif}

1) Regresi Linier Sederhana

Berdasarkan dari hasil analisis dengan menggunakan program SPSS 17 maka diperoleh hasil regresi antara Kepemimpinan dan Komunikasi terhadap Kinerja Dosen seperti pada tabel berikut :

Tabel 1

Analisis Regresi Sederhana Coefficients $^{\mathrm{a}}$

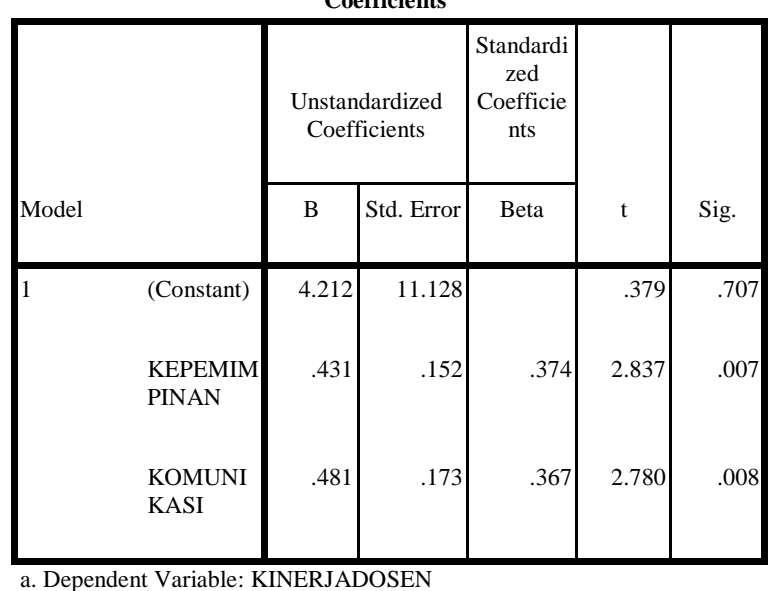

Sumber : Hasil Penelitian, diolah 2015, SPSS 
Informasi yang ditampilkan pada tabel 1 adalah persamaan regresi berganda antara variabel independen $\left(\mathrm{X}_{1}\right.$ yaitu Kepemimpinan dan $\mathrm{X}_{2}$ yaitu Komunikasi) terhadap variabel dependen ( $\mathrm{Y}$ yaitu Kinerja Dosen) yang dapat diformulasikan dalam bentuk persamaan berikut :

$$
Y=4,212+0,431 X_{1}+0,481 X_{2}+e
$$

Persamaan regresi yang diperoleh di atas dapat diartikan bahwa terdapat pengaruh positif antara Kepemimpinan dan Komunikasi dengan Kinerja Dosen di STIE Sultan Agung Pematangsiantar. Kondisi ini mengartikan bahwa variabel bebas yakni Kepemimpinan dan Komunikasi menunjukkan hubungan yang searah atau positif terhadap Kinerja Dosen, dimana setiap kenaikan variabel independen ini akan menyebabkan naiknya Kinerja Dosen dan sebaliknya apabila terjadi penurunan pada Kepemimpinan dan Komunikasi maka akan langsung menyebabkan Kinerja Dosen menurun.

\section{2) Koefisien Korelasi dan Koefisien}

Determinasi

Untuk melihat seberapa besar pengaruh variabel bebas (Kepemimpinan dan Komunikas) terhadap variabel terikat (Budaya Organisasi) dapat diketahui dari perhitungan Koefisien Determinasi $\left(\mathrm{R}^{2}\right)$ yang ditunjukkan tabel berikut dengan pengolahan SPSS versi 17 sebagai berikut :

Tabel 2

Model Summary

\begin{tabular}{|l|r|r|r|r|}
\hline Model & \multicolumn{1}{|c|}{$\mathrm{R}$} & $\begin{array}{c}\mathrm{R} \\
\text { Square }\end{array}$ & $\begin{array}{l}\text { Adjusted } \\
\mathrm{R} \text { Square }\end{array}$ & $\begin{array}{c}\text { Std. Error } \\
\text { of the } \\
\text { Estimate }\end{array}$ \\
\hline 1 & $.618^{\mathrm{a}}$ & .382 & .353 & 3.49447 \\
\hline
\end{tabular}

a. Predictors: (Constant), KOMUNIKASI,

KEPEMIMPINAN

Sumber : Hasil Penelitian, diolah 2015, SPSS

Dari tabel perhitungan koefisien determinasi diatas menunjukkan bahwa Kepemimpinan dan Komunikasi dapat menjelaskan Kinerja Dosen STIE Sultan Agung Pematangsiantar sebesar $0,382(38,2 \%)$ dan sisanya $(61,8 \%)$ dapat dijelaskan oleh faktor lain yang tidak dibahas dalam penelitian ini, seperti kompensasi, motivasi kerja, tingkat stres kerja, sistem informasi dan teknologi, pelatihan, dan faktor lainnya.

\section{3) Pengujian Hipotesis dengan uji t}

Dengan penggunaan program SPSS 17 maka hasil uji t pada penelitian bahwa nilai probabilitas signifikansi lebih kecil dari tingkat keyakinan $(\alpha=$ $0,05)$, maka hal ini menunjukkan adanya pengaruh signifikan dari variabel bebas terhadap variabel terikat yang dapat dijelaskan sebagai berikut :

Tabel 3

Coefficients $^{\mathrm{a}}$

\begin{tabular}{|c|c|c|c|c|c|c|}
\hline \multirow[b]{2}{*}{ Model } & & \multicolumn{2}{|c|}{$\begin{array}{l}\text { Unstandardized } \\
\text { Coefficients }\end{array}$} & \multirow{2}{*}{ 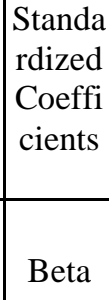 } & \multirow[b]{2}{*}{$\mathrm{t}$} & \multirow[b]{2}{*}{ Sig. } \\
\hline & & B & $\begin{array}{l}\text { Std. } \\
\text { Error }\end{array}$ & & & \\
\hline 1 & $\begin{array}{l}\text { (Constan } \\
\text { t) }\end{array}$ & 20.984 & 7.257 & & 2.891 & .006 \\
\hline & $\begin{array}{l}\text { BUDAY } \\
\text { AORGA } \\
\text { NISASI }\end{array}$ & .626 & .114 & .642 & 5.493 & .000 \\
\hline
\end{tabular}

a. Dependent Variable: KINERJADOSEN

Sumber : Hasil Penelitian, diolah 2015, SPSS

Informasi yang ditampilkan pada tabel 3 adalah persamaan regresi antara variabel independen ( $\mathrm{X}_{3}$ yaitu Budaya Organisasi) terhadap variabel dependen ( $\mathrm{Y}$ yaitu Kinerja Dosen) yang dapat diformulasikan dalam bentuk persamaan berikut:

$$
Y=20,984+0,626 X_{3}+e
$$

Persamaan regresi yang diperoleh di atas dapat diartikan bahwa terdapat pengaruh positif antara Budaya Organisasi dengan Kinerja Dosen di STIE Sultan Agung Pematangsiantar. Kondisi ini mengartikan bahwa variabel Budaya Organisasi menunjukkan hubungan yang searah atau positif terhadap Kinerja Dosen, dimana setiap kenaikan variabel Budaya Organisasi ini akan menyebabkan naiknya Kinerja Dosen dan sebaliknya apabila terjadi penurunan pada Budaya Organisasi maka akan langsung menyebabkan Kinerja Dosen menurun.

\section{4) Uji Efek Intervening}

Intervening merupakan variabel antara yang berfungsi memediasi hubungan antara variabel independen dengan variabel dependen. Untuk menguji pengaruh variabel mediasi digunakan metode analisis jalur (path analysis). Apabila pengaruh tidak langsung kepemimpinan dan komunikasi terhadap kinerja dosen melalui budaya organisasi lebih besar dibanding pengaruh secara langsung kepemimpinan dan komunikasi terhadap kinerja dosen, maka budaya organisasi bisa menjadi variabel yang mengintervening antara kepemimpinan dan komunikasi terhadap kinerja dosen. 
Untuk menghitung standard error $\mathrm{ab}\left(\mathrm{S}_{\mathrm{ab}}\right)$ digunakan rumus sebagai berikut :

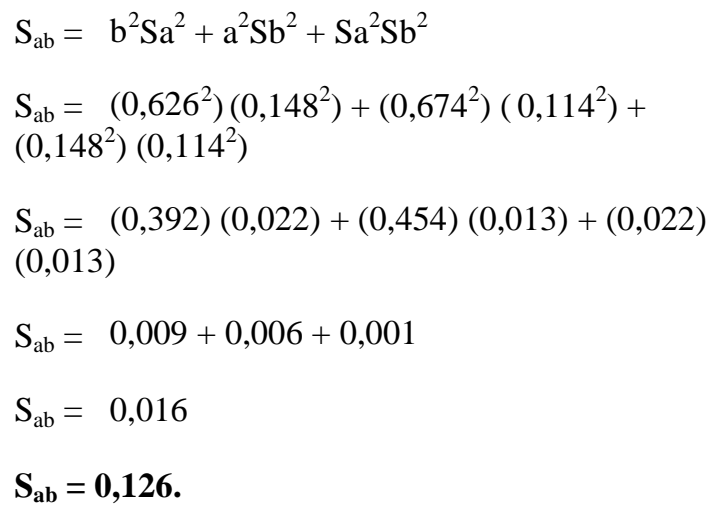

Sedangkan untuk nilai t koefisien ab adalah sebagai berikut :

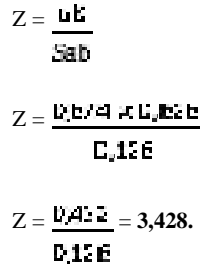

Berdasarkan hasil perhitungan nilai $\mathrm{Z}$ hitung diperoleh nilai 3,428 lebih besar dari $\mathrm{z}$ tabel dengan tingkat signifikansi 0,05 yaitu 1,96 sehingga dapat disimpulkan bahwa budaya organisasi mengintervening hubungan antara kepemimpinan terhadap kinerja dosen.

Kemudian untuk menghitung standard error bc $\left(S_{b c}\right)$ digunakan rumus sebagai berikut :

$$
\begin{aligned}
& S_{b c}=\sqrt{ } b^{2} S^{2}+c^{2} S^{2}+S^{2} S^{2} \\
& \left(0,174^{2}\right)\left(0,114^{2}\right) \\
& (0,013) \\
& S_{\mathrm{bc}}=\sqrt{0,012}+0,007+0,001 \\
& S_{b c}=\sqrt{ } 0,02 \\
& \mathrm{~S}_{\mathrm{bc}}=0,141 \text {. }
\end{aligned}
$$$$
S_{\mathrm{bc}}=\sqrt{ }\left(0,626^{2}\right)\left(0,174^{2}\right)+\left(0,716^{2}\right)\left(0,114^{2}\right)+
$$$$
S_{\mathrm{bc}}=\sqrt{ }(0,392)(0,030)+(0,512)(0,013)+(0,030)
$$

Sedangkan untuk nilai t koefisien ab adalah sebagai berikut :

$$
\begin{aligned}
& Z=\frac{t 6}{506}
\end{aligned}
$$

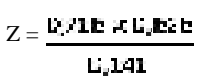

$$
\begin{aligned}
& Z=\frac{\text { DAA4E }}{\text { DiLAI }}
\end{aligned}
$$$$
\mathrm{Z}=3,177
$$

Berdasarkan hasil perhitungan nilai $\mathrm{z}$ hitung diperoleh nilai 3,177 lebih besar dari z tabel dengan tingkat signifikansi 0,05 yaitu 1,96 sehingga dapat disimpulkan bahwa budaya organisasi mengintervening hubungan antara komunikasi terhadap kinerja dosen.

\section{Evaluasi}

\section{a. Kepemimpinan pada STIE Sultan Agung Pematangsiantar}

Kepemimpinan merupakan proses yang harus ada dan perlu diadakan dalam kehidupan manusia selaku mahkluk sosial. Kepemimpinan diartikan sebagai pelaksanaan otoritas dan pembuatan keputusan. Kepemimpinan juga didefenisikan sebagai suatu inisiatif untuk bertindak yang menghasilkan suatu pola yang konsisten dalam rangka mencari jalan pemecahan dari suatu persoalan secara bersama. Variabel Bebas $\left(\mathrm{X}_{1}\right)$ kepemimpinan dipengaruhi oleh beberapa faktor dalam kuisioner. Hasil yang diperoleh variabel Kepemimpinan, responden yang menjawab kurang baik $8 \%$, baik $56 \%$, serta sangat baik $34 \%$. Dengan demikian disarankan untuk meningkatkan lagi kepemimpinan yang sudah ada karena masih ada responden yang menjawab kurang baik.

\section{b. Komunikasi pada STIE Sultan Agung \\ Pematangsiantar}

Komunikasi merupakan cara menyampaikan gagasan, fakta, pikiran, perasaan, dan nilai kepada orang lain. Komunikasi adalah jembatan arti di antara orang-orang sehingga mereka dapat berbagi hal-hal yang mereka rasakan dan ketahui. Dengan menggunakan jembatan ini,seseorang dapat menyeberangi sungai kesalahpahaman dengan selamat yang adakalanya memisahkan orang-orang. Hubungan komunikasi di STIE Sultan Agung Pematangsiantar dapat dilihat dari berbagai faktor seperti yang terdapat dalam pertanyaan kuesioner. Adapun hasil yang diperoleh untuk variabel Komunikasi adalah responden yang menjawab kurang baik $11 \%$, baik 59\%, serta sangat baik $30 \%$. Dari hasil penelitian ini jalinan komunikasi harus lebih ditingkatkan lagi karena masih ada jawaban kurang baik dari responden.

\section{c. Budaya Organisasi pada STIE Sultan Agung Pematangsiantar}

Budaya organisasi merupakan nilai-nilai dominan yang diterapkan dan dipatuhi serta dijalankan dalam suatu organisasi yang bertujuan sebagai kunci keberhasilan organisasi dalam mencapai tujuannya. Variabel Budaya Organisasi dapat dilihat dari beberapa faktor dalam kuisioner. Hasil dari kuisioner Budaya Organisasi, responden yang menjawab tidak baik $1 \%$, kurang baik $9 \%$, baik $56 \%$ dan sangat baik 34\%. Dari hasil penelitian ini sebaiknya budaya organisasi perlu ditingkatkan lagi karena masih ada jawaban kurang baik dari responden. 


\section{d. Kinerja Dosen pada STIE Sultan Agung Pematangsiantar}

Kinerja dosen adalah kemampuan untuk melaksanakan pekerjaan atau tugas yang dimiliki dosen dalam menyelesaikan suatu pekerjaannya. Variabel Kinerja Dosen dipengaruhi oleh berbagai faktor dalam kuisioner. Adapun hasil dari variabel Kinerja Dosen adalah kurang baik 19\%, baik 56\%, serta sangat baik $25 \%$. Dari hasil penelitian ini agar kinerja dosen tetap dipertahankan dan ditingkatkan lagi karena masih ada jawaban kurang baik dari responden

\section{KESIMPULAN DAN SARAN}

\section{Kesimpulan}

a. Bahwa Kepemimpinan dan Komunikasi berpengaruh signifikan terhadap Kinerja Dosen STIE Sultan Agung Pematangsiantar secara simultan. Hal ini dapat dilihat dari hasil pengujian regresi yang menunjukkan tanda positif pada persamaan sebagai berikut:

$Y=4,212+0,431 X_{1}+0,481 X_{2}+e$

Artinya semakin baik kepemimpinan dan komunikasi maka semakin tinggi kinerja dosen di STIE Sultan Agung Pematangsiantar.

b. Bahwa Budaya Organisasi berpengaruh signifikan terhadap Kinerja Dosen STIE Sultan Agung Pematangsiantar. Hal ini dapat dilihat dari hasil pengujian regresi yang menunjukkan tanda positif pada persamaan sebagai berikut:

\section{$Y=20,984+0,626 X_{3}+e$}

Artinya semakin baik budaya organisasi maka semakin tinggi kinerja dosen di STIE Sultan Agung Pematangsiantar.Berdasarkan hasil perhitungan nilai $\mathrm{z}$ hitung sebesar 3,428 lebih besar dari $\mathrm{z}$ tabel dengan tingkat signifikansi 0,05 yaitu 1,96 sehingga dapat disimpulkan bahwa Budaya Organisasi mengintervening pengaruh Kepemimpinan terhadap Kinerja Dosen STIE Sultan Agung Pematangsiantar.

c. Berdasarkan hasil perhitungan nilai $\mathrm{z}$ hitung sebesar 3,177 lebih besar dari $\mathrm{z}$ tabel dengan tingkat signifikansi 0,05 yaitu 1,96 sehingga dapat disimpulkan bahwa Budaya Organisasi mengintervening pengaruh Komunikasi terhadap Kinerja Dosen STIE Sultan Agung Pematangsiantar.

\section{Saran}

a. Variabel kepemimpinan dan komunikasi berpengaruh signifikan dan kuat terhadap kinerja dosen baik di uji dengan Uji $t$ maupun Uji Korelasi, maka STIE Sultan Agung Pematangsiantar agar lebih meningkatkan peran kepemimpinan, menciptakan hubungan komunikasi yang harmonis, menjaga kelestarian budaya organisasi dan meningkatkan kinerja dosennya.

b. Saran penulis agar STIE Sultan Agung Pematangsiantar lebih memperhatikan faktor lainya yang mendukung kinerja dosen STIE Sultan Agung Pematangsiantar seperti motivasi, kompensasi, komitmen organisasi dan faktor lainya.

c. Waktu pelaksanaan penelitian ini sangat terbatas (3 bulan). Saran penulis bagi peneliti berikutnya yang ingin melanjutkan penelitian ini adalah agar melaksanankan penelitian dengan waktu yang lebih lama lagi, agar diperoleh hasil yang lebih akurat.

\section{E. DAFTAR PUSTAKA}

Davis, 2007, Perilaku dalam Organisasi Edisi Revisi, Jakarta : CV. Haji Mas Agung.

Dessler, Gary, 2004. Manajemen Sumber Daya Manusia, Edisi 9, Jilid 1, Jakarta : Kelompok Gramedia.

H. Mintzberg, The Manager's Job: Folklore and Fact, Harvard Business Review, July-August 1975, New York.

Ferdinand, 2006, Metode Penelitian Manajemen, Semarang : Universitas Diponegoro.

Ghozali, Imam, 2005, Aplikasi Analisis Multivariate dengan Program SPSS, Buku Kedua, Edisi Pertama, Jakarta : Salemba Empat.

Luthan, Fred, 2006 .Perilaku Organisasi, Edisi ke 10, Yogyakarta : Penerbit Andi.

Robbins, Stephen P. - Judge, Timothy A., 2008, Perilaku Organisasi, Jilid 1 - 2, Edisi 12, Jakarta : Salemba Empat.

Rojai, dan Risa Maulana Romadon, 2013, Panduan Sertifikasi Guru Berdasarkan UndangUndang Guru dan Dosen, Jakarta : Dunia Cerdas. 